\title{
Literatura no PROFLETRAS: caminho de formações mútuas
}

\author{
Literature in the PROFLETRAS: a mutual way of formation
}

\author{
Ana Crélia Dias* \\ Universidade Federal do Rio de Janeiro \\ Rio de Janeiro, RJ, Brasil \\ Fernando Maués** \\ Universidade Federal do Pará \\ Belém, Pará, Brasil
}

\begin{abstract}
Resumo: O PROFLETRAS, Mestrado Profissional em Letras em rede, cuja configuração inicial contava com 37 polos nas cinco regiões, insere-se no conjunto de iniciativas federais que, na última década, buscaram promover a integração entre as universidades e a escola de educação básica. Concebido como programa de formação continuada stricto sensu para professores do ensino fundamental da rede pública, a pós-graduação objetiva qualificar a prática pedagógica de língua materna. No caso específico da Literatura, tão marginalizada no contexto de uma Educação escrutinada por métricas cartesianas, habilidades e competências mensuráveis - ao que o texto literário e toda a arte são tão reativos - e, ao lado disso, do afastamento radical do que se focaliza nas licenciaturas e o que se realiza nas escolas, o programa tem desafio importante a enfrentar. É das transformações, é da formação conjunta e mútua de docentes universitários e da escola básica que trata este trabalho. A partir de um suporte teórico que inclui estudiosos da formação docente como Tardif e Raymond (2000), Messina (2001) e Contreras (2002) e, principalmente, das relações entre Literatura e Educação e da formação de leitores, como Candido (2002; 2004), Chiappini (2005), Lajolo (1992) e Bajour (2012), aliado à coleta de relatos de docentes e discentes do programa, que buscamos refletir sobre os movimentos provocados pela formação e seus resultados nas relações com o texto literário e o ensino de literatura, em todos os níveis de ensino. O encontrado foi uma transformação que tem seus efeitos sentidos tanto na escola, quanto no ensino superior, na medida em que novas práticas e conhecimentos têm resultado da conjunção dos saberes acadêmicos com aqueles profissionais dos professores.
\end{abstract}

Palavras-chave: Formação de professores; mestrado profissional; PROFLETRAS; Literatura e ensino.

\begin{abstract}
PROFLETRAS, a master's degree in Portuguese Language and Literature, works in a 37 centers network in all five Brazilian regions and is part of a bunch of federal initiatives that, in the last decade, sought to promote integration between universities and elementary schools. Conceived as a stricto sensu education program that targets public elementary school teachers, it aims to qualify teacher's work. In the specific case of literature, so marginalized in the context of an education scrutinized by Cartesian metrics, measurable skills and competences - to which the literary text and all arts are so reactive - and, in addition, to the radical disruption between what is focused on undergraduate degrees and what takes place in schools, the program has major challenges to face. This work studies the transformations caused by the reunion and mutual formation of university teachers and the ones of elementary school. From a theoretical support that includes researches of teacher education as Tardif and Raymond (2000), Messina (2001) and Contreras (2002) and, mainly, of the relations between Literature and Education and the readers formation, as Candido (2002; 2004), Chiappini (2005), Lajolo (1992) and Bajour (2012), added to a collection of reports from teachers and students of the program, we seek to think about the movements caused by the formation and its results in the
\end{abstract}

*Doutora em Literatura Brasileira, professora da Universidade Federal do Rio de Janeiro. E-mail: anacrelia@gmail.com.

***Doutor em Literatura Portuguesa, professor da Universidade Federal do Pará. E-mail: fmaues@ufpa.br. 
relations with the literary text and the teaching of literature at all levels of education. The found was a transformation that has its effects felt in both scholar and elementary levels.

Keywords: Teatcher training; teacher master; PROFLETRAS; Literature and teaching.

\section{INTRODUÇÃO}

Para falar do impacto de um Programa como o PROFLETRAS, é preciso lembrar que ele se insere em um conjunto de ações do governo federal que, desde 2010, promoveram o encontro entre a universidade e a escola pública de educação básica. Ao lado de PIBID e PARFOR, o PROFLETRAS impulsionou a universidade a um movimento motivador de suas ações e também de suas recusas, uma vez que a superespecialização acadêmica emparedou docentes em suas pesquisas específicas e mesmo que a contragosto, muitas vezes - naquilo que a universidade pensava ser a formação adequada de professores da educação básica: acumulação de conteúdos de formação específica, os quais, muitas vezes, chegavam a particularidades muito eruditas para o mundo real do chão das escolas, sem que se fizesse uma reflexão sobre os limites entre o conhecimento do professor e aqueles dirigidos aos seus alunos.

Antonio Candido, em "Discurso de paraninfo", texto dirigido a formandos de Letras de 1947, já apontava certa desconfiança em relação a uma prática universitária que se aproximava tanto da busca dos títulos quanto se afastava da relação com as necessidades sociais formativas, as quais constituem demandas reais das ações das universidades. $\mathrm{O}$ autor critica uma posição de superioridade da universidade em relação à escola, reiterando o compromisso da educação pública com a sociedade que viabiliza seu funcionamento, premissa tão básica, mas muitas vezes distante devido a um afastamento das instituições dos princípios gestadores do sistema educacional público:

[...] somos um grupo de privilegiados a destacar-se da comunidade por vezes miserável de nossos patrícios pela oportunidade que tivemos de nos cultivar (...) em escolas sustentadas pelo trabalho desta mesma comunidade. A ela, portanto, nos devemos em primeiro lugar, e tudo o que fizermos para o nosso progresso pessoal terá alcance realmente humano na medida em que nos cometermos à tarefa de saldar esta grande dívida. (2002, p. 311).

O crítico enuncia ainda que potencial de construção coletiva dos conhecimentos da universidade pode ser ameaçado pelo emparedamento do saber nas especificidades da cátedra, e pela dificuldade de comunicar as ideias e colocá-las à prova de outras, o que pode significar, inclusive, certo gozo pelo hermetismo como sinônimo superioridade de inteligência:

Na vida universitária - onde o hábito de ensinar pode conduzir ao dogmatismo e os títulos conquistados à pretensão de onisciência - acentuam-se geralmente os processos de afastamento da vida com hipertrofia da atividade intelectual, porque não raro a disciplina universitária repousa sobre algumas deformações prévias do espírito. (2002, p. 311). 
A crítica encaminha-se, portanto, para certa cisão entre os objetivos da educação pública e aquele que é seu destinatário e, ao mesmo tempo, deveria ser quem comunica as necessidades de mudança de paradigmas e de novas pesquisas. Isolada das vozes necessárias ao movimento dialético do conhecimento, a universidade, segundo o autor, perpetua a “incapacidade juvenil de fundir ação e conhecimento" (p. 313). Reconhecendo que o trabalho intelectual se situa no plano da abstração, alerta para a necessidade de que a instituição universitária se desvie do perigo do "pedantismo, isto é, o culto do saber desligado da existência." (p. 313).

Quase quatro décadas depois do texto de Antonio Candido, Ligia Chiappini escreveu Invasão à catedral, que mais tarde se chamaria Reinvenção da Catedral, obra em que indicou preocupações sobre a formação do estudante de Letras, acentuadas pela "lógica da eficácia e da produtividade" (2005, p. 189). Denunciando o desmantelamento da universidade, evidenciado desde a década de 60, num movimento de sucessivas reformas, conclui que o desprestígio da literatura e das artes em geral é uma extensão do desprestígio das ciências humanas de maneira geral, que passam a exercer papel de adorno. Assim, à lógica da superespecialização acadêmica, já sinalizada por Candido e reiterada por Osman Lins na década de 70, em Do ideal e da glória: problemas inculturais brasileiros, soma-se a dinâmica da submissão das pesquisas a uma cultura de novo modelo econômico, em que a universidade "reproduz a divisão do trabalho compartimentandose em áreas estanques do saber" e sofre aparelhamento "para produzir mão de obra barata e lucro". Por mais que tenha havido e ainda haja resistência a esse modelo, a lógica de mercado, incorporada pelas agências de fomento, que submeteram as ciências humanas a modelos de avaliação próprios das ciências exatas, e o curso de Letras, especialmente no tocante à literatura, incorpora métodos mais descritivos do objeto, em detrimento da leitura e da escuta da palavra poética, desautorizando criação (inclusive a interpretativa e crítica) e investindo na repetição de juízos consagrados:

Assim, um curso de Letras, que deveria propiciar o nascimento e o amadurecimento das artes da palavra, é um lugar onde se escreve para provas, se lê para nota, se disserta no vazio, para um interlocutor artificial - o professor - sobre textos de que é preciso falar antes de deixa-los falar a nós. (CHIAPPINI, 2005, p. 190).

Um curso de Letras que situa a arte literária numa esfera de contemplação de muitos e aproximação de poucos, situado em universidades em crescente movimento de precarização, acentuou a distância entre a proposta da formação inicial e a realidade da escola. Mais ainda, a cristalização do ensino pautada em níveis - fundamental, médio e superior - pareceu impregnar a educação de hierarquia, sem abertura ao diálogo. É preciso ressaltar, portanto, que a aproximação entre universidade e escola, a partir de 2010, se deveu, mais que a esforços e escolhas individuais (ainda que estas tenham ocorrido), a uma política pública que elegeu, como caminho para a qualificação do ensino, tanto básico como superior, fomentar a integração entre os níveis. 


\section{IN MEDIA RES: UMA SALA DE AULA DO PROFLETRAS}

O professor está na sala com 23 colegas que, naquela circunstância, são seus alunos. Há, entre eles, quem pouco passou dos 20 anos de idade, outros que se aproximam dos 60; todos atuam na escola pública. A maioria tem mais experiência no ensino médio - nível em que se simula um lugar para a literatura -, mas também com horas no fundamental, o que garante o acesso ao Programa. Ninguém percebe o texto literário como objeto central de sua prática docente, nem mesmo os que se identificam como professores de Literatura.

Estamos nessa sala os que amamos a literatura, mas nem por isso sabemos "ensiná-la" - nem na escola, nem na universidade. Estão também os que não têm interesse especial pelo texto literário e, para estes, os desafios para inseri-lo significativamente na sala de aula seriam superados mais facilmente pelo apagamento que, em grande medida, já se pratica.

O grupo é heterogêneo, selecionado por um processo nacional em larga escala, e compartilha o desejo sincero de ampliar seus repertórios teóricos, metodológicos e melhorar suas práticas. A eleição do foco e dos caminhos a seguir, porém, não é pacífica. Há um solo minimamente comum a fundar antes de qualquer avanço: o lugar da literatura na formação humana e escolar; na infância, na juventude, na vida adulta.

A questão, que se apresenta para nós de maneira tão decisiva, foi negligenciada por pelo menos quatro séculos tal o prestígio do livro e da leitura, incluindo as "artes verbais" - para não usar anacronicamente o termo literatura -, como repositório privilegiado da cultura humana (CHATIER, 2003). A leitura era signo de prestígio. Encarados como virtuosos ou perigosos, não havia dúvidas sobre o poder das narrativas de ficção, dos poemas, do drama sobre o espírito humano.

$\mathrm{O}$ avanço do audiovisual, no século XX, provocaria rearranjos nos sistemas de valores dos bens culturais e seus suportes. Os presságios sombrios para a literatura, da decadência de sua leitura e ensino, vêm sendo difundidos pelo menos desde meados do século. Sartre, ainda em 1949, afirmou que nada garantia sua imortalidade; Bloom, em 1994, previa a diminuição progressiva dos departamentos de Estudos Literários até se tornarem do tamanho do que eram, na época, os de Estudos Clássicos. Neste início de século XXI, obituários se avolumam: Todorov (2007) proclama que a literatura está em "perigo"; William Marx (2005) e Perrone Moisés (2011) indicam seu "longo adeus"; Millet (2007) fala em "desencanto"; Sallenave (2008) alerta que "não amamos ler". Neste contexto, surgem, como nunca, obras que buscam justificar a necessidade da literatura, por que lê-la e estudá-la, como as de Compagnon (2009) e Jouve (2012).

Voltamos àquela sala de aula, na segunda década do século XXI. Nela, não há consenso sobre o que pode a literatura, sobre seu papel, sobretudo na escola. A discussão elenca, superficialmente, qualidades como emocionar, ampliar o vocabulário, promover a concentração, o conhecimento de estilos de época, da história nacional, das culturas de outros tempos e lugares; uns poucos mencionam a apreciação estética e o reconhecimento de recursos e estruturas típicos do uso artístico da linguagem, na chave das teorias formalistas. 
Há muitos títulos disponíveis sobre a questão, dos já mencionados Compagnon (2009) e Todorov (2007) ao clássico "Direito à literatura", de Cândido (2004), e os tantos textos escritos por Zilberman (1981; 1987) e Lajolo (1982, 1993), desde os anos 1980 - sem esquecer A convivência com os textos, publicado ainda em 1970 por Lívia Ferreira. No contexto de um mestrado profissional, de um grupo formado por licenciados em Letras, a leitura da bibliografia deveria bastar. Não basta. Como lembram Tardif e Raymond,

Uma boa parte do que os professores sabem sobre o ensino, sobre os papéis do professor e sobre como ensinar provém de sua própria história de vida, principalmente de sua socialização enquanto alunos. Os professores são trabalhadores que foram imersos em seu lugar de trabalho durante aproximadamente 16 anos (em torno de 15.000 horas), antes mesmo de começarem a trabalhar. Essa imersão se expressa em toda uma bagagem de conhecimentos anteriores, de crenças, de representações e de certezas sobre a prática docente. (2000, p. 216-217).

A imersão de uma vida em um universo em que o texto literário é tratado, em todos os níveis de formação, do fundamental à licenciatura, como "pretexto" (LAJOLO, 1982), cristaliza um habitus, "um sistema de disposições duráveis e transponíveis que, integrando todas as experiências passadas, funciona a cada momento como uma matriz de percepções, de apreciações e de ações" (BOURDIEU, 1983, p. 65). De fato, a longa convivência com a literatura como conjunto textual instrumentalizado para a alfabetização e o letramento, a normatização ortográfica e sintática, a análise linguística e de fenômenos comunicativos, a exemplificação de conceitos da historiografia literária ou da teoria literária, a ratificação de variados modelos críticos cristaliza "percepções" e "apreciações" e condiciona "ações" de forma coercitiva e "durável".

Nesse cenário, encontrar um lugar para a literatura nas salas de aula tem como pré-requisito superar uma tradição que estabelece seu não lugar, sua marginalização, sua instrumentalização. A tarefa é incerta, difícil de replicar em larga escala, mas incontornável. Juntos, aqueles 23 professores precisam atravessar para uma "terceira margem", posta além daquela das teorias linguísticas e literárias, mas também da outra, em que bastam a fruição e uma certa compreensão mínima, padronizada do que "o autor quis dizer".

Os resultados dessa travessia aparecem numa evolução sensível. Nos últimos seis anos, professores universitários não apenas se aproximaram da educação básica, conheceram melhor suas carências e qualidades a partir da escuta dos colegas-alunos, mas também aprenderam com colegas de outras instituições que compõem a rede nacional do Programa, com experiências diversas e contextos muitas vezes incomparáveis. Também, vindos de uma formação que pouco contemplava a discussão do ensino-aprendizagem, acumularam bibliografia e vêm amadurecendo a reflexão acerca dela.

Os mestrandos, por sua vez, escreveram dissertações que de fato buscaram soluções para suas questões na escola a partir da integração criativa de novos conhecimentos teóricos, suas experiências profissionais, o diálogo com colegas. Nem sempre puderam tornar a experiência duradoura, por muitos fatores (discutidos adiante), 
mas consistentemente incorporaram novas práticas aos seus cotidianos. Ainda, vêm formando redes de apoio profissional e acadêmico que os alimentam e sustentam durante os atropelos que o dia-a-dia escolar acarreta.

\section{FORMAÇÃO CONTINUADA PARA QUEM? O OLHAR DO DOCENTE}

A construção do espaço da literatura no currículo do PROFLETRAS não foi diferente do que costuma ser de maneira geral: um processo litigioso, que demanda esforços argumentativos que se não se podem localizar na esteira cientificista, tampouco cabem no discurso da subjetividade sem contornos:

[...] as instituições de ensino tendem a colocar a literatura em um lugar de litígio: ela, como manifestação estético-ético-artístico-cultural, precisará sempre se defender para existir. Precisará defender-se das censuras dos temas, entre os mediadores de leitura dos leitores pequenos; das muitas necessidades de conhecimento de gêneros textuais e categorias gramaticais nas aulas de língua portuguesa do Ensino Fundamental II; da exclusividade da historiografia literária e da perspectiva enciclopédica no Ensino Médio; dos olhos da crítica e da teoria como únicos modos de interpretação da obra na graduação. (DIAS: 2016, 212).

Ao rol de situações litigiosas em que se encontra a literatura, elencado acima, o PROFLETRAS, em sua gênese, acrescentou outra, que diz respeito ao não reconhecimento dos estudos literários no ensino fundamental - segmento cujos docentes são o público-alvo do Programa. A batalha travada para garantir um espaço para a literatura nesse nível de ensino encontrava barreiras especialmente entre os que defendiam ser o texto literário mais um dentre os inúmeros gêneros textuais, cujos estudos já estavam previstos no Programa.

Ultrapassada a barreira inicial, o Programa se configurou com uma disciplina de literatura, "Leitura do texto literário", entre as sete obrigatórias, e mais duas optativas "Literatura e ensino" e "Literatura infanto-juvenil". A dificuldade passou a ser, então, a de encontrar docentes de Literatura que quisessem se engajar em um mestrado profissional, uma vez que os estudos literários estão muito afastados da relação com a educação básica, como se pode entrever nas linhas teóricas em que se circunscrevem os documentos oficiais, por exemplo. Assim, em muitos polos, as disciplinas de Literatura por vezes ficaram a encargo de professores da educação básica (dos colégios de Aplicação), dos professores de língua estrangeira e até de alguns da área de Linguística. A perspectiva teórica do letramento literário justificou-se, portanto, pelo conjunto heterogêneo de profissionais reunidos para construir as ementas das disciplinas, a grande maioria sem conhecimento sedimentado ou experiência nas questões da educação básica, principalmente sobre o lugar, ali, da literatura, que "se agarraram ao que as mãos tinham mais próximo" "

${ }^{1}$ É Carrascoza, na tão bela como indispensável "Suíte acadêmica: apontamentos poéticos para elaboração de projetos de pesquisa em Comunicação", que declara: "Começa-se, seja o que for, agarrando-se ao que as mãos têm de mais próximo - somos todos náufragos, então cada um que pegue o que puder à sua maneira ou no desespero" (2016, p. 64) 
projetos de leitura que dominavam as livrarias e revistas da época. Tal perspectiva se deixava notar tanto nas bibliografias dos cursos quanto naquelas das primeiras dissertações defendidas.

Mesmo entre os professores de Literatura que participaram do Programa desde o início, o desafio de pensar as relações da literatura com a educação básica se apresentaram em dois aspectos, a ausência de repertório teórico para iluminar as discussões nesse novo cenário e a dificuldade de sair das especificidades de pesquisa. Nós, docentes de IFES, habituados a trabalhar com grupos de alunos provenientes muitas vezes de vestibulares duros e, em geral, muito seletivos, no relativo conforto físico de nossas instituições, fomos arrastados para espaços de ensino diversos e para o contato com estudantes cujo conhecimento prático da profissão docente impunha o diálogo e o confronto permanente entre ideais e possibilidades efetivas de atuação, entre o conhecimento e a democratização do conhecimento através da docência.

$\mathrm{Na}$ ocasião da primeira avaliação do Programa pela CAPES, muito se falou sobre o impacto do PROFLETRAS, na maioria dos casos em relação à repercussão das ações na educação básica. Para tentar construir uma narrativa sobre o cotidiano do Programa até então - e posteriormente refletir sobre ela - fizemos uma pesquisa entre docentes de Literatura, para que avaliassem o significado, em suas carreiras e práticas pedagógicas, de atuar no Mestrado Profissional em Letras. Indicamos a seguir alguns excertos que podem ser bastante esclarecedores das possíveis reverberações de uma política pública no interior das práticas universitárias.

Uma primeira reflexão diz respeito ao estranhamento para lidar com discussões sobre o sentido de ensinar o que ensinávamos - ou julgávamos ensinar a nossos estudantes; e, mais ainda, admitir o descompasso entre o que cunhávamos "formação de professores" - transmissão das nossas pesquisas específicas - e a demanda curricular, ética e estética que a escola básica convocava:

Eu, com graduação, mestrado e doutorado na Universidade de São Paulo, desde muito cedo envolvido em temas de literatura medieval e clássica, acreditava que formar professores era trazer, para discussão com alunos de graduação e pós, as questões mais importantes da área, sugerindo dos textos mais relevantes e clássicos aos mais recentes e inovadores - e acreditei, por mais de uma década, estar realizando, na Universidade Federal do Pará, o mesmo bom trabalho que gente da estatura de um Bosi, um Hansen haviam feito comigo na USP.

De repente - de repente mesmo -, foi-me revelado por alunos de PIBID, PARFOR, PROFLETRAS que quase nada do eu me esforçava tanto para trazer para meus cursos universitários chegava, de fato, às aulas da escola; quase nada contribuía, de verdade, para a prática docente daqueles que eu tentava formar. Pior que isso: a tragédia não se resumia aos meus cursos, mas à maioria do que se via num curso de licenciatura em Letras. Foi um dos momentos mais difíceis da minha vida profissional e pessoal. Tomado por um sentimento de inutilidade e falta de sentido, tive que me perguntar, duramente, qual era, afinal, meu trabalho. ${ }^{2}$

${ }^{2}$ Depoimentos de docentes e discentes não serão identificados. 
O desprestígio da formação pedagógica nos cursos de Letras, em especial no tocante aos estudos literários, que, na luta para não pedagogizar a literatura, acabam por não lhe admitir a possibilidade de escolarização, conservaram-se em postura muito distante de qualquer reflexão sobre os sentidos da presença da Literatura na escola. A questão da relativa inocuidade da formação inicial de professores já era assumida por Tardif e Raymond há duas décadas:

$\mathrm{Na}$ América do Norte, percebe-se que a maioria dos dispositivos de formação inicial dos professores não consegue mudá-los nem abalá-los. Os alunos passam através da formação inicial para o magistério sem modificar substancialmente suas crenças anteriores sobre o ensino. E, tão logo começam a trabalhar como professores, sobretudo no contexto de urgência e de adaptação intensa que vivem quando começam a ensinar, são essas mesmas crenças e maneiras de fazer que reativam para solucionar seus problemas profissionais" (TARDIF \& RAYMOND, 2000, p. 217).

$\mathrm{Na}$ gênese de um programa de formação continuada, parece estar engendrada certa rigidez na ocupação dos espaços de ensino e aprendizagem, isto é, a universidade ocupará o papel de quem ensina, o que certamente constitui-se como equívoco, uma vez que a interlocução no processo ensino-aprendizagem é sempre móvel, reservado o compromisso ético de ser o professor um especialista. O caráter de formação continuada a que se propõe o PROFLETRAS encontrou descontinuidade não só entre o corpo discente, mas também entre os docentes:

O PROFLETRAS me colocou de frente para a lacuna de minhas aulas de Literatura na licenciatura em Letras, especialmente no que tange a minha completa inexperiência em relação à literatura infantil e juvenil, além das literaturas africanas e afro-brasileiras e indígenas. Ou seja, o PROFLETRAS me retirou da zona de conforto da minha especialização acadêmica para me fazer voltar a uma relação mais abrangente e orgânica, que se constitui como necessária para a formação de professores para a educação básica. Via-me muito distante, internalizando um discurso comum entre meus pares: 'formar professor é coisa da faculdade de educação. Nós formamos o pesquisador.' Como se o professor não fosse um pesquisador... como se eu pudesse me dar a esse luxo, sendo professora de um curso de licenciatura... como se os egressos de Letras tivessem enorme mercado de trabalho como apenas pesquisadores. Daí eu pensei no quanto a formação foi subtraída de mim também, quando era estudante, e, nesse sentido, as leituras do PROFLETRAS foram tão inaugurais para mim quanto eram para os alunos, nas primeiras turmas.

A colega professora deixa entrever o caráter de formação continuada que o Programa representa em sua atividade como docente e aponta equívocos em relação à formação inicial de que toma parte. Os questionamentos sobre os sentidos de formar professores parecem tê-la retirado de um lugar de conforto em relação à tarefa e, principalmente, terem propiciado conscientização sobre a responsabilidade de sua negligência, mesmo que antes não sabida com clareza, na formação docente, de que ela mesma se vê vítima, assim como repetidora dessa prática que autoriza uma concepção autoritária, em que se sobrelevam vaidades e vontades acadêmicas em detrimento do necessário empenho em formar docentes. O ethos do docente da educação básica, nessa 
concepção negligenciadora, parece inferiorizado e, certamente, isso se reflete em seu lugar no corpo social a que chamamos educação.

A defesa da literatura no currículo do PROFLETRAS passou a ser uma fala recorrente, reconhecida, sobretudo, no que significou para certa militância em relação ao tangenciamento da literatura na escola, sobretudo no Ensino Fundamental, evidenciadas no espaço ocupado nos documentos oficiais, e o Programa foi também força impulsionadora para outras ações, relativas à pesquisa:

Entrar para o PROFLETRAS parece ter-me colocado numa batalha em que a defesa da Literatura na escola é o principal propósito. A ideia de "Direito à literatura" mobiliza professores-alunos, que mobilizam seus estudantes. A força disso que chamo de fenômeno pode ser vista na reativação do GT Literatura e Ensino, da ANPOLL, nos inúmeros dossiês de revistas acadêmicas dedicados à pesquisa e nos eventos (A ABRALIC tem dedicado espaço para isso). Em tempos de autoritarismo crescente, a arte torna-se urgência.

A fala do professor parece indiciar que o PROFLETRAS também foi responsável por impulsionar uma reação a um distanciamento da área de estudos literários das demandas sociais que, embora sejam mais urgentes nesse momento histórico, sempre existiram. Regina Zilberman, assim como Antônio Cândido, Osman Lins e Lígia Chiappini denunciaram essa atitude de afastamento das cátedras de seus estudantes e, sobretudo, do que significa formar professor num país de desigualdades alarmantes. É importante sobrelevar na fala do professor a força política construída no grupo de estudos literários do PROFLETRAS, que teve como consequência uma série de ações, para ampliação e qualificação do debate na área. No sentido dessa conexão mais sensível e necessária da educação com as artes, entendida como direito, a partir, principalmente, do texto de Antônio Cândido, "O direito à literatura", outra colega fala do exercício necessário quando do trabalho com o PROFLETRAS, e no significado deste exercício no atual momento histórico:

Após ler o texto de Candido, no trecho em que ele diz, em 1988, que a barbárie continua presente, em crescimento, mas que, pelo menos, havia certo constrangimento para não elogiá-la em público ou socialmente, na mesmo hora lembrei do elogio feito pelo atual presidente, em 2016, durante o voto pelo impeachment: ele elogiou o coronel Ustra, um reconhecido torturador, responsável pela morte e desaparecimento de dezenas de pessoas. Bem, a partir dessa relação entre o tempo de expectativa de Candido e o tempo atual, me perguntei como humanizar com a literatura, como fazer com que esse direito fosse também uma reivindicação, uma força capaz de desnaturalizar o elogio da barbárie.

Nas palavras de Antonio Candido, a humanização promovida pelo ensino da literatura, por exemplo, é um processo que 'confirma no homem aqueles traços que reputamos essenciais, como o exercício da reflexão, a aquisição do saber, a boa disposição para com o próximo, o afinamento das emoções, a capacidade de penetrar nos problemas da vida, o senso da beleza, a percepção da complexidade do mundo e dos seres, o cultivo do humor. A literatura desenvolve em nós a quota de humanidade na medida em que nos torna mais compreensivos e abertos para a natureza, a sociedade, o semelhante.' (2004, p. 180) Trabalhar a memória e a tarefa infinita de humanizar a nós mesmos e ao outro é o que me mobiliza, atualmente, em tempos tão sombrios e que parecem durar uma eternidade. 
A colega professora enfatiza, em sua fala sobre o PROFLETRAS, certa urgência de que a literatura e as artes em geral retomem o espaço da emancipação do pensamento, preconizado por Cândido. Interessante que o anacronismo do texto - o constrangimento à época em fazer elogio à barbárie, prática institucionalizada em nosso tempo - parece reforçar mais ainda a necessidade de trazer à baila a defesa do direito à literatura como potência humanizadora, a qual não deve ser entendida como docilizadora, tampouco salvacionista. Para tanto, a universidade não poderá produzir, ler e fazer crítica literária de si para si: é preciso comprometer-se com o compartilhamento de seu saber, colocado em diálogo na formação inicial dos professores. A conexão necessária da universidade com a educação básica é um ponto pacífico das escritas dos professores do Programa. Entretanto, outro impasse diz respeito à viabilidade de construir práticas dialogadas para leitura e estudo de literatura em instituições escolares precarizadas, sem bibliotecas, com professores desestimulados pela desproporcionalidade entre cargas horárias, condições de trabalho e salário.

Mais que "dar aulas", era preciso garantir a pertinência do que se discutia nas aulas e a conexão do conhecimento com as necessidades dos licenciandos, não apenas como gente que iria se dedicar à pesquisa, fazer mestrado e doutorado, mas, sobretudo, para a maioria, que saía da graduação para, imediatamente, atuar na escola de ensino fundamental e médio. Era preciso não perder de vista a relevância dos conteúdos para a educação básica e como estes poderiam ser levados às crianças e jovens. Há sentido em ler cantigas trovadorescas, novelas de cavalaria, Gil Vicente, Camões, Vieira, Gregório com jovens de 15, 16 anos? Qual é? Como fazê-lo? De que forma se pode promover a construção de sentidos em textos tão afastados - historicamente, culturalmente, linguisticamente - da vida dos estudantes do século XXI? Se eu, especialista nas "artes verbais antigas", não fosse capaz de construir essas respostas, como professores que apenas passaram por esses conteúdos, no meio de tantos outros, na diversa e criativa "balbúrdia" de uma licenciatura, seriam? Como relegar este papel a um colega que, muitos semestres depois, ministraria "oficinas" e outras "práticas" de ensino de literatura?

Mais que isso, muito da atual teoria acerca da "formação de leitores" encontra dificuldades - às vezes intransponíveis - de concretização nas salas de aula reais habitadas por docentes, mestrandos do PROFLETRAS ou licenciandos do PARFOR e PIBID. Como organizar em círculo os estudantes atirados em salas superlotadas, com carteiras pesadas? Como criar um ambiente favorável à leitura com iluminação muito precária e uma temperatura desumana? Como ler textos integrais em escolas sem biblioteca, na qual sequer chegam os livros didáticos? Como exigir que um professor com 800 alunos, distribuídos em 17 turmas, em três turnos, se forme como leitor, com todo o peso e repertório necessário para transmitir a leitura aos estudantes? Como prever muitas horas de leitura em sala, sem cobranças de tarefas ou análise linguística, na premência de exigências sobre o cumprimento de Programas decididos em instâncias superiores?

As reflexões do colega professor colocam em xeque as dificuldades que um Programa implementado em grande escala, num país com dimensões continentais como o nosso, enfrenta no plano de sua execução no cotidiano. Planejar ementa e diretrizes para trabalho nos diferentes espaços deste país significa ignorar muitas variáveis regionais, culturais, econômicas e até geográficas. Há polos do PROFLETRAS em que os estudantes se deslocam por mais de $500 \mathrm{~km}$ para ter aulas, o que exige reorganização institucional; além disso, o Programa encontra muitas vezes uma realidade de 
profissionais massacrados com carga horária excessiva, e nem sempre as Secretarias de Educação cumprem o compromisso firmado de diminuir a carga horária do professor para que ele estude, conforme previsto na Lei de Diretrizes e Bases da Educação Nacional, de 1996. A avaliação do professor revela, portanto, a concepção hierárquica das estruturas gestoras do sistema educacional no plano macro, as quais generalizam ações e ignoram especificidades regionais

Para colegas cujas formações e orientações da prática pedagógica já apontavam para um jogo de relações engendradas numa concepção formativa para atuação na educação básica, o PROFLETRAS representa, de certa forma, um continuum de coerência:

Acredito que um Programa como o PROFLETRAS contribui de uma maneira muito significativa para a conexão entre a universidade e a escola de educação básica. De um lado a universidade ganha por saber o que acontece efetivamente nas salas de aula brasileiras e isto é fundamental para repensarmos os currículos de Licenciaturas em Letras, que são muito pouco articulados com os saberes necessários para se atuar na educação básica. De outro lado estes profissionais têm a oportunidade de entrar em contato com novas teorias de ensino de língua / literatura e produção textual. Também é uma oportunidade para que estes profissionais construam redes de contato, de troca de saberes entre si, de partilha de práticas inovadoras de ensino.

No meu caso, o PROFLETRAS se conecta com minha atuação na formação de professores: na Didática e Prática de Ensino de Português e Literatura e no Programa de Iniciação à Docência de Língua Portuguesa. Isto me possibilita investir em pesquisas ligadas ao ensino de literatura na escola de educação básica de um modo bastante coerente.

O professor ressalta em suas palavras o ganho que significa para a universidade o trabalho com a força viva de diálogo com a educação básica, e aponta de certo modo a necessidade de repensar os currículos de Letras. O olhar privilegiado de quem atua nas disciplinas da área de Educação e participa de outro Programa de incentivo à formação docente, nesse caso a inicial e não a continuada, parece colocar em concretude o que chama de coerência em sua prática profissional.

Nas falas de alguns colegas professores do Programa, outra escola, viva e presente, contrapõe-se àquela da qual o senso comum aponta preponderantemente as faltas. E o trabalho coletivo não coloca a escola básica em lugar de desprestígio, ao contrário, convoca-a para tomar parte num processo de construção de saberes dos sujeitos envolvidos. Os professores da educação básica são as referências da prática da professora:

Eu gosto muito de trabalhar no PROFLETRAS! Primeiro porque trabalhamos com professores os quais estamos sempre usando como referência em nossas aulas e pesquisas na Universidade: professores do ensino básico formados nas mais diferentes instâncias e das mais diferentes formas com as mais diferentes trajetórias pedagógicas e de leitura. Então como lidamos com perspectivas didáticas da literatura é possível sentir como cada um vai construindo sentidos para sua trajetória de leitor e de professor, como vai entendendo criticamente o trabalho que realiza na escola e como se descobre livre para mudar, se quiser. Sinto vitalidade e engajamento nas nossas aulas. O diálogo é intenso entre nós. Os professores estão lá para aprender e estudar na acepção mais potente para o meio 
acadêmico: o esforço intelectual para observar e compreender os dados da realidade, ou seja, construir um entendimento capaz de explicar a realidade e torná-la mais ética. As limitações, contudo, advêm das condições materiais com que se deparam, principalmente a falta de tempo para se dedicar a essa vivência, uma vez que não conseguem licença da escola para estudar.

O sentido de a universidade de construir um esforço de construção coletiva de potencialidades intelectuais, como dizia Cândido, parece ter lugar nas aulas do PROFLETRAS ministradas pela professora. A presença dos professores da escola no Programa retira a educação básica da condição de objeto de pesquisa para do lugar de sujeitos pesquisadores de suas práticas. A percepção, por parte dos mestrandos, de suas práticas e a iluminação teórica necessária elevam a qualidade das reflexões sobre o cotidiano escolar em uma via de mão dupla, em que se beneficiam sobremaneira escola e instituição universitária.

\section{4- PROFESSOR DE LITERATURA NO ENSINO FUNDAMENTAL}

No mesmo pequeno barco em que vai o professor universitário, estão os docentes da escola básica, mestrandos, que "mareiam as velas", movem-se em contrapeso, seguram o leme. Navegam ao sabor de ventos muitas vezes violentamente discordantes dos estudos literários, das teorias de ensino-aprendizagem, dos documentos oficiais, das demandas institucionais, das vivências dos colegas e das suas próprias. Tampouco seguem em direção única as correntes de suas expectativas e seus desejos. Nesse aspecto, estendem-se por um gradiente que vai da intenção de "não serem incomodados" (POUND, 1976, p. 79) em seus habitus à formulação de maneiras completamente novas - e arriscadas, e incômodas - de tecer relações com a literatura em sala de aula. Ressalte-se: é um gradiente, poucos estão nos tons sólidos das extremidades.

O cenário líquido e pouco positivo que acabamos de descrever contrasta com a percepção que muitos estudos têm sobre os Programas de formação continuada de professores no Brasil, conjunto no qual se inserem os mestrados profissionais como o PROFLETRAS: instâncias que promovem o treinamento mecânico de habilidades específicas, a partir de conhecimentos construídos em alçadas muito distantes da escola básica, com soluções padronizadas ensinadas como fórmulas prontas para resolver os dilemas complexos da realidade docente (SANTOS, 2018, p. 41-43). Dessa perspectiva, Contreras adverte para o "o processo contínuo de desqualificação" do trabalho do professor, "produto da crescente regulação, tecnicidade, controle a que se encontram submetidos" (2002, p. 45).

Ainda que o autor se refira especificamente a um fenômeno dos sistemas educacionais anglo-saxões na virada do século, é possível estender a preocupação ao Brasil de 2019. Aqui, a produção abundante de documentos reguladores oficiais em todas as esferas governamentais, da Lei de Diretrizes e Bases da Educação aos Parâmetros Curriculares Nacionais e à Base Nacional Curricular Comum, aliada à proliferação de Programas de formação de professores em diversos níveis - inicial, 
continuada, lato e stricto sensu -, de variadas durações e objetivos, e à onipresença dos livros didáticos (com edições "do professor", contendo as respostas esperadas e roteiros de trabalho prontos) como suporte quase exclusivo da atividade em sala de aula provocaram, também, o sequestro da autonomia docente - ou, nas palavras do mesmo Contreras, a "perda progressiva do controle sobre o conteúdo e finalidade de ensino, produto de uma crescente separação entre sua concepção e execução" (2002, p. 46).

Tal disjunção entre quem elabora Programas e diretrizes, escolhe conteúdos e objetivos e quem os aplica, efetivamente, em salas de aula, tem limitado o professor institucionalmente e, com o passar dos anos, culturalmente, a executar aulas que não pensou, a exigir dos alunos respostas sobre as quais nem mesmo ponderou, mas que trazem a chancela das letrinhas azuis em fonte cursiva do livro do professor.

Messina, ao tratar da implantação de "inovações" pedagógicas através das tantas reformas que, literalmente, se abatem sobre os docentes, escreve:

\begin{abstract}
No marco das reformas educacionais, as inovações têm sido mudanças desde cima, mecanismos de ajuste mais que de satisfação das demandas dos atores. Segundo Tedesco (1997), as inovações têm sido esforços "responsivos", referidos a marcos gerados nos níveis centrais dos sistemas de ensino. Esses marcos não só regulamentam como homogeneízam a inovação. Nesse sentido, Fullan (2000) destaca que os professores têm de se haver com uma quantidade inumerável de propostas inovadoras, com o correlativo de dependência que cria essa situação. Além disso, segundo Fullan, ao mesmo tempo que a escola está bombardeada por inovações, o novo não tem lugar. (2001, p. 227).
\end{abstract}

A conclusão de Messina é tão paradoxal quanto certeira: ao prescindir da contribuição do docente que está na linha de frente da educação básica, ao ignorar completamente suas demandas em nome de debates acadêmicos via de regra pouco sensíveis à escola, os Programas de formação e as reformas prescrevem "inovações" que nunca são de fato implantadas porque carecem de sentido no ambiente escolar e de pertencimento por quem deveria executá-las. No máximo, ali, Programas e métodos são maquiados, simulando adesões aos "novos" paradigmas.

Em um encontro, naquela sala de aula do PROFLETRAS, em que discutíamos a pertinência dos Programas de ensino e planos de aula concretos dos mestrandos, observamos, repetidamente, Programas que traziam, como objetivos, "formar leitores críticos; promover a apreciação estética; refletir sobre os usos da língua e seus contextos sociais etc." e, na lista de conteúdos, uma longa relação: "adjunto adnominal; adjunto adverbial; locuções adjetivas etc.”. Os documentos trazidos pelos professores em formação testemunhavam a convivência formal dos novos parâmetros com velhas práticas, o drama de diretrizes impostas aos cabeçalhos, mas incapazes de se realizarem na vida concreta da escola.

Observada a defasagem entre o ideal dos documentos e o real da vida, faz sentido a proposta de Domingues (2009), para quem a promoção de mudanças através da formação contínua necessita levar em consideração as reais demandas dos professores, iniciantes e veteranos; adotar a participação de todos na elaboração de propostas e discussões pedagógicas, na organização de projetos de estudos e das reuniões de trabalho. A formação precisa se tornar parte das condições de trabalho dos docentes, 
envolvendo os sistemas de ensino e assegurando condições institucionais técnicas e materiais para o desenvolvimento profissional permanente.

Outro aspecto importante a considerar na formação dos professores, além de garantir-lhes o protagonismo, é não menosprezar suas qualidades intelectuais ou a complexidade de suas demandas. "É preciso oportunizar ao educador não leituras simplificadas e superficiais, mas aprofundamentos teóricos, metodológicos, conhecimento amplo a respeito de teorias várias" (SILVA; PETRONI, 2011 p. 160). Em outras palavras, é fundamental que as enormes responsabilidades que pesam sobre docentes da escola básica sejam sustentadas por uma formação teórica sólida, vasta, que alimente suas escolhas e leituras do contexto em que vive. Não se alcança autonomia e protagonismo pela via do aligeiramento e da sonegação de saberes.

$\mathrm{O}$ que se estabelece, então, como ideia para um processo formativo saudável e efetivo - que tem, aqui, o sentido de promover uma qualificação real da prática docente, que amplie as formas de relacionamento com o conhecimento, com os alunos, com a escola -, é um exercício reflexivo e democrático no qual o conhecimento acumulado na academia esteja em evidência e seja incorporado na sua complexidade, mas não sujeite aquele saber construído pelos mestrandos em anos de experiência no ambiente escolar, como aluno ou professor; uma interação na qual as vozes de autores legitimamente consagrados alimentem um coro com as vozes dos professores, não as calem. Além disso, que tenha como motor as curiosidades e angústias dos docentes diante das questões que a profissão lhes impõe e que promova a elaboração de caminhos e soluções particulares, que respeitem seus contextos específicos e até a personalidade de cada indivíduo.

Mais ainda, no caso da formação de professores de literatura, junta-se aos pilares do protagonismo e da reflexão teórica profunda a experimentação da leitura de literatura como prática significativa, autônoma e social. É necessário ler literatura e conversar sobre o lido sem a obrigatoriedade de qualquer atividade ou tarefa suplementar.

Dessa perspectiva, era preciso promover, naquela sala de um Programa de pósgraduação stricto sensu voltado à formação de professores, a experiência de ler. Muitos, ali, viviam pela primeira vez a leitura de narrativas ficcionais e poemas em ambiente de educação formal como atividade autônoma e, ao final de cada texto, perguntavam: e agora, qual a atividade? Como seremos avaliados? Mais do que um movimento consciente, era como se o corpo, mal iniciada a leitura, mal despertos os devaneios tão fundamentais de que fala Petit (2009), já se inclinasse para fora do texto, em direção a algum destino pragmático que justificasse a obra.

Foram necessários vários encontros - seis, oito; dois meses - para que o grupo realmente deixasse encarnar - incorporar-se à carne e ao edifício cognitivo, ao habitus - a prática de leitura desconectada de uma atividade posterior. A mudança de paradigma, então, dava-se mais pelo exemplo, pela experimentação, pela vivência do processo e o testemunho de seu êxito em muitas perspectivas e matizes do que pela aplicação de teorias que, vindas de fora e do alto, colonizassem o grupo pela autoridade. Retomando a metáfora com que se inicia esta seção, era preciso que os professores governassem o leme (escolhessem o repertório), tomassem decisões acerca dos ventos e correntes 
(determinassem o ritmo de leitura e a direção das conversas), enfim, convivessem com o mar para que aprendêssemos, todos, algo mais sobre navegar. Enfim, formar docentes para as práticas com o texto literário na escola, na mesma chave proposta por Iser para o "ato da leitura", não era "algo a ser explicado, mas sim um efeito a ser experimentado" (1996, p. 34).

Tal experiência de leitura do texto literário, obviamente, não está destituída da dimensão acadêmica e é, retomando a proposta de Bajour, "alimentada com teorias, já que para reconhecer, apreciar e potencializar os achados construtivos [das obras] se torna produtivo o manejo de alguns saberes teóricos por parte do mediador." (2012, p. 40). Em nosso caso, de especialistas das Letras, o conhecimento específico da área precisa ir além de "alguns saberes"; deve ser amplo e profundo o suficiente para não depender de conteúdos Programados para uma aula, mas para poderem, na medida do possível, emergirem, na sala de aula, motivados pelas situações que o próprio texto literário evoque nos alunos. Em resumo, um conhecimento teórico sólido que esteja a serviço da literatura, não o contrário.

Adotar essa perspectiva não é confortável. É mais fácil preparar uma aula sobre tipos de narradores, sobre aspectos do Barroco ou sobre o efeito de sentido de alguns ritmos do verso e usar textos literários selecionados previamente como exemplos. Ao compartimentalizar conteúdos, tem-se maior domínio sobre o que acontece na aula. Ao contrário, quando permitimos que o texto e a leitura particular de uma turma, com problemas e curiosidades específicas, guiem nosso trabalho, temos menos controle e, claro, precisamos ter incorporado mais e melhor a teoria para atuar satisfatoriamente na maioria dos casos. É Bajour, novamente, quem nos fala dessa mobilização da teoria a partir da escuta dos leitores:

Uma escuta sensível, que valorize os modos pelos quais cada leitor se refere ao contato com metáforas, perspectivas inusitadas, alterações temporais, elipses etc., pode ser uma situação para que essas descobertas sejam colocadas em diálogo com algumas denominações técnicas. Trata-se de uma maneira de transmitir culturas e pôr à disposição saberes técnicos sobre a arte que não pretende ser "a verdade" acerca dos textos. A teoria é mobilizada a partir daquilo que os leitores dizem sobre os textos, e não de antemão: quando ela precede a leitura, condiciona e fecha sentidos. (BAJOUR, 2012, p. 40-41).

Note-se, boa parte do que se vem propondo tem pouca correspondência com o que se observa nas escolas e universidades, em aulas ou treinamentos. Como já se disse, a descoberta desses caminhos, a partir da leitura de especialistas e escritores, das conversas em sala e fora dela, da reflexão um tanto obsessiva sobre nossa própria prática pedagógica é ainda uma tarefa em construção. Muitos encontros, nas salas de aula do Programa e em eventos externos com os mestrandos, fluem, quase como encantados; outros fracassam miseravelmente em obter engajamento e promover achados estéticos, teóricos, metodológicos. Felizmente, com o passar dos anos, aqueles dias comparecem cada vez mais; estes nos assombram menos. Os movimentos feitos, os efeitos sofridos até aqui podem ser demonstrados pela mudança no desenho de disciplinas, pela reformulação quase completa das indicações bibliográficas e das atividades propostas, pela atuação e pelos relatos dos egressos. 
É importante ressaltar que estes, entrevistados ${ }^{3}$ para projeto que busca avaliar o impacto do Programa em suas práticas pedagógicas, ao responderem acerca das disciplinas do PROFLETRAS que mais contribuíram para a qualificação de suas práticas na escola básica, indicaram as disciplinas de Literatura ${ }^{4}$. O motivo desse impacto nos interessa e, para pensar sobre ele, devemos voltar às expectativas dos mestrandos acerca do curso.

As sondagens revelam que, ao se candidatarem ao Programa, os professores se sentiam excluídos do "meio onde o conhecimento estava circulando" e viam no mestrado profissional o oráculo que solucionaria suas angústias. Uma professora lembra: "Eu acreditava que aqui no PROFLETRAS eu iria encontrar uma chave pros meus problemas. Que, como era voltado para professor, então achei que iria dar certo. [...] Então, quando eu voltar desse mestrado[, pensei], vou resolver parte desses problemas". Outro acrescenta:

Eu esperava [ao ingressar no PROFLETRAS] realmente conhecer mais, né? Ter mais conhecimento. Esperava também ter contato com outros colegas, com professores. Eu esperava saber como é que estava a questão do ensino porque, na verdade, você está aqui numa ponta da prática e você não sabe o que está sendo estudando, pesquisado em nível de academia.

Percebe-se que a posição assumida, ao entrar no mestrado, era a de quem "não sabe" e que, na "academia", encontraria quem sabe "da questão do ensino" e "tem a chave" para solucionar seus problemas - uma posição passiva e de excessiva humildade que seria matizada no decorrer do curso.

A literatura, nos relatos das expectativas, chama atenção pela ausência. Tendo como foco o ensino fundamental, ninguém menciona o texto literário como objeto particular de interesse. Nenhum dos entrevistados, de fato, refere-se à literatura como parte de seu trabalho - o que tornava urgente, nos primeiros encontros do curso, o convencimento de que professores de língua materna no ensino fundamental são professores de literatura, têm o texto literário como objeto privilegiado de estudo e convivência.

Tal argumento não convence pela autoridade, nem da fala do professor universitário, nem dos escritos de Candido, Lajolo, Zilberman, Compagnon, De Maria, Chambers, Todorov, entre tantos. Por mais cristalinos, por mais que façam sentido e se debrucem sobre a necessidade humana do ficcional, da arte, todo o repertório teórico se choca contra os anos vividos na escola pelos mestrandos, nos quais a literatura, como literatura, está apagada.

\footnotetext{
${ }^{3}$ As entrevistas, de modelo semiaberto, gravadas em vídeo e com cerca de 40 minutos de duração, foram realizadas em 2017 e 2018 e alcançaram 19 egressos das duas primeiras turmas do PROFLETRAS da UFPA. Os trechos transcritos aparecem no texto entre aspas.

${ }^{4}$ Os entrevistados cursaram, como todos os mestrandos de suas turmas na UFPA, três disciplinas da área: a obrigatória, "Leitura do texto literário", mais duas optativas, "Literatura e ensino" e "Literatura infantojuvenil".
} 
Dessa situação de conflito entre saberes acadêmicos e a experiência de vida dos mestrandos resultaram fricções. A forma como tais fricções foram tratadas explica, segundo nos parece, o relevo da literatura entre todo o repertório do mestrado. É preciso ressaltar que a maioria dos mestrandos chegou ao Programa já bastante carregada de leituras e cursos de formação continuada de curta e média duração. Neles, outras questões foram focalizadas, mais ligadas ao letramento (em particular, suas "deficiências"), aos gêneros discursivos e textuais, ao desenvolvimento de competências e habilidades linguísticas. Boa parte dessas formações tinha caráter prescritivo, seguindo e resultando em roteiros, sequências didáticas, projetos de leitura e escrita.

Tal abordagem, segundo entendemos, se se mostra útil para instruir acerca de determinados temas, é flagrantemente inadequada para tratar qualquer objeto artístico. O texto literário, nessa categoria, demanda algo de que nossas iniciativas formativas pouco dispõem: tempo - tempo e dedicação; tempo e desejo de intimidade; tempo e, nas palavras de Todorov, amor; sobretudo, tempo.

As disciplinas de literatura do PROFLETRAS se estendem por cinco meses de encontros semanais. Nestes, se não nos apressa um fim útil imediato ou a urgência em transmitir metodologias e roteiros "prontos para usar", demora-se o suficiente para permitir a experiência densa, lenta, incerta, mas inescapável de leitores encontrando-se com obras literárias demora-se o suficiente para que os professores reconheçam suas formas particulares de se relacionarem com cada narrativa ou poema, para que inventem suas abordagens específicas a partir das vivências e das sugestões dos estudos acadêmicos.

Nisso os cursos do mestrado se diferenciam das formações rápidas, com metas verificáveis por métricas cartesianas, nas quais não há espaço real nem para a literatura, nem para o protagonismo dos docentes.

Ao retornar para a sala de aula, um egresso comenta:

Eu não sabia como trabalhar, nunca aprendi. Muitas vezes eu pegava conto, pegava romance, mas mencionava só o fragmento e trabalhava com isto: análise linguística, gramatical. E quando eu passei no PROFLETRAS, no fundo eu fui me dar conta do que eu estava fazendo. Eu estava perdendo uma dimensão de literatura muito importante com os meus alunos. E depois eu comecei a tomar contato com esses conhecimentos, de metodologias e teorias, e comecei a levar pra sala de aula. Foi aí que me dei conta que como poderia ser, realmente, o trabalho.

Outra acrescenta: "Hoje, por exemplo, uma melhora que consegui lá é que meus alunos estão frequentando a biblioteca, estão pegando os livros que eu indico e, mais ainda, eles estão lendo."

O percurso do PROFLETRAS não apenas colocou a leitura do texto literário (na sala de aula, na biblioteca, em outros espaços da escola) no horizonte pessoal e profissional dos professores, mas também promoveu a autonomia destes diante dos currículos escolares e materiais didáticos disponíveis, como relata uma professora:

O que [o mestrado] acrescentou na minha prática foi me sentir mais segura das minhas atitudes, decisões dentro da sala de aula e tomar o espaço da sala de aula como meu e não 
"o que posso fazer", não somente me orientar pelo livro ou por aquilo que vejo na formação mas, dentro da minha sala de aula, sondar os meus alunos e ver quais a são as necessidades e a partir das necessidade montar o meu planejamento.

Um colega concorda:

Porque antes eu não planejava, [...] a gente só se preocupava com o livro didático do professor, com as questões prontas, com as questões acabadas - e se o aluno não respondesse aquilo que tu querias, ainda tinha a cara de pau de considerar errado. Eu não tinha essa concepção. Quebra-se essa maldição, vamos dizer assim, e passa a planejar as suas aulas. [...][Sinto-me] muito mais autônomo e muito mais liberto, muito mais livre e feliz com isso.

Nem tudo, obviamente, são relatos de "liberdade" e "felicidade". Vários egressos mencionam os múltiplos entraves que se impõem diante das tentativas de promover a leitura literária na escola, que vão das condições materiais (ausência de acervo, ambientes de leitura escuros e quentes) à falta de apoio do corpo técnico e dos colegas, que atinge sobretudo as professoras, em mais um cruel recorte de gênero que as oprime mesmo neste espaço tomado por mulheres que é o ensino fundamental.

Outras barreiras são impostas por instâncias superiores. Uma professora, que se mostra orgulhosa da promoção de leitura realizada na biblioteca de sua escola, satisfeita pela produção de livros artesanais com textos originais de alunos, com a repercussão de suas atividades em matéria da TV Cultura local, desanima com as novas normas para sua atuação profissional, que ficará mais limitada a estudantes "com dificuldades de leitura" e assumirá caráter de "reforço":

A cada ano vem lá uma nova determinação do sistema. Este ano... antes, nós trabalhávamos em um projeto aberto. Nós pegávamos, elaborávamos o projeto [...], nós socializávamos o projeto e os alunos vinham voluntariamente. Este ano mudou um pouco diante do edital que nós recebemos: nós iremos trabalhar com alunos com dificuldade de leitura. Então, nosso público alvo eles já reduziram. Ele vem um pouco contra aquilo que a gente pensa como mediação de leitura. [...] os alunos que vão trabalhar no projeto, este ano, vão ser indicados pelos professores. Nós vamos trabalhar tipo reforço [fazendo no ar o sinal de aspas quando pronuncia 'tipo reforço'].

Agora, com esse edital que veio do SISMUBE [Sistema Municipal de Bibliotecas Escolares de Belém], [...] com essa documentação, já mudou um pouco nosso trabalho. [...] A biblioteca, enquanto biblioteca, ela é aberta ao público. $\mathrm{O}$ aluno vem, pesquisa livremente. Agora eles estão tendo essa obrigatoriedade. [...] eles querem três horas semanais com o aluno. Eles estabelecem o calendário de março a setembro e eles querem no final esse produto, esse resultado que nós temos que apresentar no chamado relato de experiência, em que nós temos que apresentar o que foi que nós fizemos. [...] quer dizer, muito papel, muito documento e acaba que... [acaba levantando o canto da boca em sinal de desaprovação]

A frustração da professora é visível por ver sua prática autoral, desenvolvida progressivamente pela conjunção entre seus estudos acadêmicos e a experimentação na escola, ser desfigurada pelas normas de um edital que a enxerga como integrante acéfalo e passivo do corpo educacional. 
Os embates contra um sistema enrijecido têm, no entanto, sido algumas vezes enfrentados coletivamente, o que expressa outra peculiaridade do Programa. Ao se organizar em turmas fechadas, que seguem juntas durante todo o curso; ao se configurar em espaço bastante democrático para diálogos e contribuições dos mestrandos, o PROFLETRAS tem se revelado ambiente favorável ao estabelecimento de laços profissionais e afetivos. Diante das desconfianças em seus locais de trabalho, alunos da primeira turma vêm se organizando para realizar seminários nas escolas, a fim de se legitimarem mutuamente e divulgarem o estofo acadêmico que sustenta as práticas que vêm adotando. Um egresso explica:

Eu juntei todos os nossos colegas daqui que se formaram no PROFLETRAS e fizemos um grande seminário aqui na escola. Uma semana, cada um dos novos mestres, professores do Estado e do Município daqui de Belém. Trabalhamos com esta comunidade, com os professores daqui.

Entre êxitos e dificuldades, há um saldo a comemorar. Nas práticas relatadas nas entrevistas, descritas nas dissertações e observadas in loco, professores têm promovido significativamente a leitura do texto literário na escola de ensino fundamental. Adotam um horário (de uma ou duas aulas) fixo semanal reservado exclusivamente para a leitura de literatura, com grande aceitação e participação dos alunos; a comunidade escolar também tem sido envolvida em projetos de bibliotecas itinerantes, círculos de leitura e sacolas de livros.

Note-se, se considerarmos o gradiente de interesses e desejos mencionado no início da seção, é natural que as experiências de duas dezenas de indivíduos resultem em práticas diversas, que vão desde a qualificação profissional de quem já amava a literatura, trazia-a na vida e passou a levá-la para a escola até os que entenderam os argumentos mas não foram sensibilizados a ponto de aderir, passando por uma maioria que se descobriu leitora de literatura e empreende um grande esforço para propiciar o mesmo aos seus alunos.

No início de nossos encontros, naquela sala, perguntamo-nos "que farei eu com esta espada?" - ou com este livro, ou com tantos livros. Erguemos e, é verdade, não podemos dizer que "fez-se", mas que se foi fazendo, que segue sendo feito, que não para - o que, no atual cenário, é algo a celebrar e disseminar.

\section{CONSIDERAÇÕES FINAIS}

É preciso não esquecer, neste ponto do trabalho, um fenômeno que se encontra nas raiz do programa que é nosso objeto e na de muitos outros: a universidade, ao propor uma formação continuada para docentes da educação básica, partiu de uma concepção vertical de transmissão de conhecimento, supondo que os professores da escola seriam qualificados pela aquisição saberes teóricos, quase como repetição da graduação ou, mais ainda, teriam suas "deficiências" superadas através do treinamento em novas metodologias, práticas inovadoras ou outros modismos que refletiam muito mais uma adesão da escola a um modelo radicalmente hierarquizado, gestado fora e 
acima dela, do que a uma concepção de fato transformadora. Na verdade, faltava a ambas as partes uma construção epistemológica que transitasse nos caminhos entre teoria e prática, tensionando conflitos e fronteiras numa relação dialética e construtora de desvios a uma prática reificada e reificadora dos sujeitos.

Pelo se escreveu até aqui, parece-nos que o percurso no PROFLETRAS, para professores universitários e da educação básica, vem sendo uma longa, contínua e pouco cartesiana experiência de aprendizagem cuja maior contribuição é abalar crenças teóricas e hábitos profissionais ao valorizar a o vivido a par do lido, ao apostar mais na construção coletiva de abordagens e princípios acerca da inserção do texto literário na escola que na prescrição de modelos, passos, diretrizes. É das fricções entre teorias de autores que pouco pisaram na sala de aula e o conhecimento de professores para quem parte importante do saber acadêmico foi sonegada que têm sido gestadas novas - e também redescobertas antigas, tradicionais - maneiras de relação com o literário em ambientes de educação formal e fora deles. É dessa realocação da literatura na vida e na prática pedagógica que, de fato, vem a ampliação e a qualificação do trabalho com a o texto literário.

É importante, ainda, ressaltar que aquilo que os docentes entrevistados revelaram entender por ser "bons professores" pouco tem a ver com aquisição de habilidades e competências, com o aumento de eficiência e eficácia, com a elevação de determinada métrica avaliativa, com o conhecimento de sequências e métodos. Sentir-se um bom profissional foi expresso, sobretudo, como a conquista de um significado para seu trabalho. Docentes que por tanto tempo avaliavam sua prática profissional como fracasso, que qualificavam como frustradas suas tentativas mais elevadas - os alunos não liam, não aprendiam, não se interessavam, não importavam propostas de leituras canônicas ou não, sacolas literárias, idas a biblioteca, leitura compartilhada, etc. - agora sentem, muito visceralmente, que leitura de literatura não é um "problema resolvido", mas que ganhou significado em suas salas de aula. Em escolas públicas de bairros periféricos, em contextos muito adversos - para usar a expressão de Petit (2009) - a leitura de narrativas, versos e dramas tem dado voz a alunos e professores há muito atirados em um mundo com muitas regras, muita métrica, muito conteúdo - e também muito silêncio.

A conquista desses colegas da escola básica, nesse sentido, é também a dos colegas universitários. Ao darem sentido a suas práticas, os mestrandos ajudam seus professores a encontrar sentido para suas próprias, nas salas da licenciatura, na pósgraduação.

Como resultado de um percurso aberto, não de um programa aplicado; de choques e encontros intersubjetivos, com colegas e teóricos, não da sujeição a verdades consagradas em círculos de "alto conhecimento", os êxitos de uma turma, de alguns professores, de um indivíduo são apenas parcialmente mensuráveis e não têm a garantia de poderem ser replicados, o que gera enormes incômodos no contexto de uma Educação tão metrificada. Não há muito o que fazer a esse respeito, o que não é mau.

Como programa governamental em grande escala, em rede, o PROFLETRAS precisa dar conta da diversidade de formação, interesses, expectativas de corpos 
docentes e discentes de cada instituição, inclusive das diferentes personalidades, que são incontornáveis e, por mais insistentes as tentativas, não são homogeneizáveis por diretrizes estritas. Um esforço de engessamento não resolve as precariedades professores sem curiosidade, fechados, sem densidade de leituras não se tornam melhores por força de um currículo - e pode obliterar riquezas, opondo barreiras a encaminhamentos criativos e elaboração de soluções particulares. Cabe às agências avaliadoras, à rede nacional apontar direções, mas não constranger.

Como mencionamos no início deste trabalho, o PROFLETRAS, junto com outros programas, deriva de uma diretriz governamental: promover a aproximação da universidade com a escola, colocar na mesma sala professores de todas as esferas para debater saberes acadêmicos e práticos. Esse tem sido o motor da qualificação. O que acontece em cada sala, principalmente quando se trata do texto literário, depende tanto do humano que ali se encontra quanto de parâmetros curriculares.

É preciso, por fim, lembrar que o ideal de uma relação dialética entre uma teoria vinda da pesquisa e um saber prático, nascido da vivência e da reflexão sobre ela; o de uma síntese entre uso de instrumentos legítimos legados pela cultura humana (que inclui a ciência) e a recriação particular deles por cada indivíduo (profissional, aluno) está longe de ser novidade. Paulo Freire já escrevia em suas Cartas a quem ousa ensinar, originalmente de 1993:

Recusando qualquer interpretação mecanicista da História, recuso igualmente a idealista. A primeira reduz a consciência à pura cópia das estruturas materiais da sociedade; a segunda submete tudo ao todo-poderosismo da consciência. Minha posição é outra. Entendo que estas relações entre consciência e mundo são dialéticas. (1997, p. 26)

Se o ideal é, na verdade, antigo, sua concretização é um processo que vimos construindo, com êxitos aqui e ali, como o programa do qual tratamos e que precisam se avolumar.

\section{REFERÊNCIAS}

BLOOM, H. O cânone ocidental: os livros e a escola do tempo. Trad. Marcos Santarrita. Rio de Janeiro: Objetiva, 2001

BOURDIEU, P. Sociologia. (organizado por Renato Ortiz). São Paulo: Ática, 1983.

CANDIDO, A. Discurso de paraninfo. In.: Textos de intervenção. São Paulo, Duas Cidades, Ed. 34, 2002.

CANDIDO, A. O direito à literatura. In.: Vários escritos. Rio de Janeiro: Ouro sobre azul, 2011.

CARRASCOZA, J. A. Suíte acadêmica: apontamentos poéticos para elaboração de projetos de pesquisa em Comunicação. In: MATRIZes. v. 10, no 1, jan./abr. 2016, São Paulo, p. 57-65 [DOI:http:/ /dx.doi.org/10.11.606/issn.1982-8160.v10.i1p.57-65]

CHARTIER, R. Leituras e leitores na França do Antigo Regime. Tradução Álvaro Lorencini. São Paulo: UNESP, 2003.

CHIAPPINI, L. Reinvenção da catedral. São Paulo, Cortez, 2005.

COMPAGNON, A. Literatura para quê? Trad. Laura T. Brandini. Belo Horizonte: UFMG, 2009. CONTRERAS, J. A autonomia de professores. São Paulo: Cortez, 2002. 
DIAS, A. C. P. Literatura e educação literária: quando a literatura faz sentido(s). Cerrados. Dossiê Ensino de Literatura: tensões, polêmicas e processos. Revista do Programa de Pós-graduação em Literatura. Universidade de Brasília. Ano 25. 2016.

FERREIRA, L. A convivência com os textos: unidades no ensino de Literatura em nivel médio. Assis: Faculdade de Filosofia Ciências e Letras de Assis, 1970

FREIRE, P. Professora sim, tia não: cartas a quem ousa ensinar. São Paulo: Olho d'água, 1997.

ISER, W. O ato de leitura. Uma teoria do efeito estético. Trad. Johannes Kretschmer. São Paulo: Ed. 34, 1996. v.1-2.

JOUVE, V. Por que estudar literatura? Trad. Marcos Bagno e Marcos Marcionilo. São Paulo: Parábola, 2012.

ISER, W. O ato da leitura: uma teoria do efeito estético. Vol. 1. Trad. ]ohannes Kretschmer. São Paulo: Editora 34, 1996.

LAJOLO, M. Usos e abusos da literatura na escola. Rio de Janeiro: Globo, 1982.

LAJOLO. M. Do mundo da leitura para a leitura do mundo. São Paulo: Ática, 1993.

LINS, O. Do ideal e da glória: problemas inculturais brasileiros. São Paulo, Summus, 1977.

MARX, W. L'adien à la littérature. Histoire d'une dévalorisation. XVIIIe - XXe siècle. Paris: Éditions de Minuit, 2005.

MESSINA, G. Mudança e inovação educacional: notas para a reflexão. Trad. Isolina Rodriguez. Cadernos de Pesquisa, n. 114, novembro/2001 2001. p. 225-233

PERRONE-MOISÉS, L. O longo adeus à literatura. Ilustríssima - Folba de São Paulo, 10/07/2011 [Disponível em: https://www1.folha.uol.com.br/ilustrissima/941210-o-longoadeus-a-literatura.shtml]

PETIT, M. A arte de ler: ou como resistir à adversidade. Trad. Arthur Bueno e Camila Boldrini. São Paulo: Ed. 34, 2009.

POUND, E. A arte da poesia: ensaios escolhidos. São Paulo: Cultrix/EDUSP, 1976. SALLENAVE, D. Nous, on n'aime pas lire. Paris: Gallimard, 2008

SANTOS, Z. Mestrado Profissional em Letras: contribuições à formação docente no discurso dos egressos da Universidade Federal do Pará. PPGED - UFPA, 2018. [Dissertação de Mestrado] SARTRE, J. P. O que é literatura? Trad. Carlos Felipe Moisés. $3^{a}$ ed. São Paulo: Ática, 2004.

SILVA, R. A.; PERONI, M. R. A formação continuada do docente de língua portuguesa e o programa GESTAR I: a proposta oficial as necessidades do professor. Revista Moara, n. 36, jul/dez 2011.

TARDIF, M.; RAYMOND, D. Saberes, tempo e aprendizagem do trabalho no magistério. In: Educação \& Sociedade, ano XXI, n 73, dez/2000.

TODOROV, T. A literature em perigo. Trad. Caio Meira. $2^{\text {a }}$ ed. Rio de Janeiro: DIFEL, 2009. [Originalmente publicado em francês em 2007].

ZILBERMAN, R. (org). Leitura Em Crise Na Escola: As Alternativas Do Professor. Porto Alegre: Mercado Aberto: 1982.

ZILBERMAN, R. A literatura infantil na escola. São Paulo: Global. 1981.

Recebido em: 20/10/2019

Aprovado em: 07/11/2019

Publicado em: 19/12/2019 